\title{
ENGİNÜN, İnci (2019). Ahmet Hamdi Tanpınar. İstanbul: Dergâh Yayınları. 292 s.
}

\author{
Ebul Vefa USTA*
}
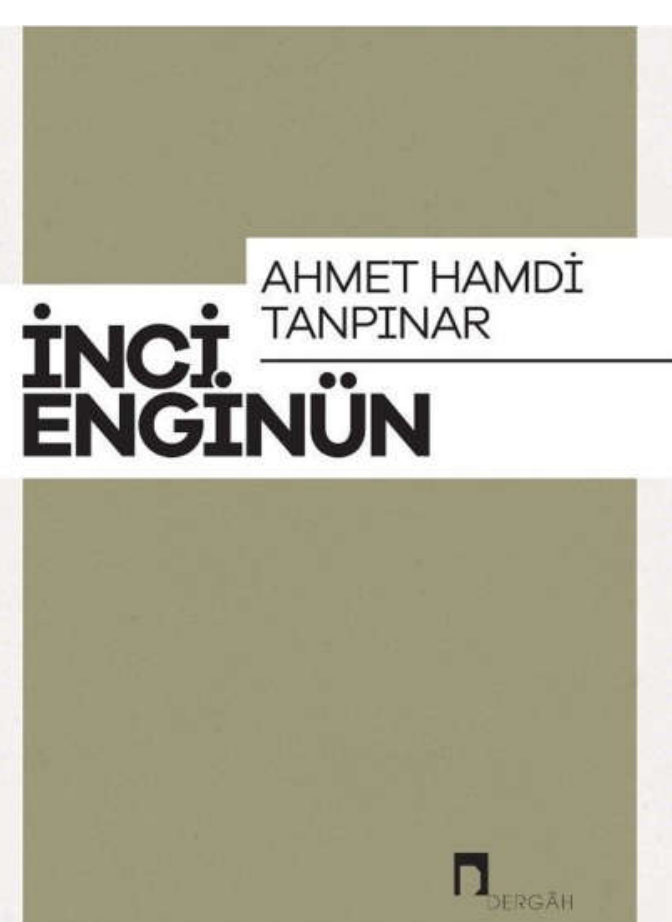

Sükût suikastına uğradığının üzerinde defaatle duran Ahmet Hamdi Tanpınar'ı en iyi anlatabilecek kişilerin başında İnci Enginün gelir. Kendisi Mehmet Kaplan'ın talebeliğini yaptığı gibi bizzat Ahmet Hamdi Tanpınar'ın derslerinde de bulunur. Mehmet Kaplan'ın Ahmet Hamdi Tanpınar vefat ettikten sonra eline geçen günlüklerini Zeynep Kerman ile beraber İnci Enginün'e vermesi de bunun göstergelerindendir.

Enginün bu kitabı oluştururken Tanpınar hakkındaki hemen hemen her bilgiye ve yaşanmışlıklara ulaşır. Kendisinin Tanpınar hakkındaki konferansları, röportajları, yayımladığı makaleler ve Tanpınar'dan kalanlar ise bu eserde birleşir.

Enginün'ün Ekim 2019 yılında Dergâh yayınlarından yayımlanan Ahmet Hamdi Tanpınar adlı eseri önsöz, üç ana bölüm ve dizin olmak üzere toplamda 292 sayfadan oluşur. Muhtevası genel olarak Ahmet Hamdi Tanpınar'ın eserlerinden, hayatından, sanatından, sanatçılığından ve ondan kalanlardan edinilen bulgular üzerine yoğunlaşır.

Üç ana bölüm “Tanpınar ile ilgili incelemelerin yer aldığı ilk bölüm”, “Tanpınar'la İlgili Söyleşiler" ve "Tanpınar'ın Kitaplarına Önsözler ve Bazı Değerlendirmeler" üst başlıklarıyla tasnif edilir ve kendi içlerinde alt başlıklara ayrilır.

Kitabın önsözünde Enginün Tanpınar'a öncelikle Mehmet Kaplan penceresinden baktığını, Tanpınar'ın "Bir Gül Bu Karanlıklarda" şiirinden çok etkilendiğini, Kaplan'dan sonra ilgisinin arttığını, ona yaşarken gelmeyen şöhretinin Mehmet Kaplan sayesinde vefatından sonra geldiğini anlattıktan sonra bu kitabın bir şablonunu burada zikreder/değinir. (s. 9-11)

“Tanpınar Hakkındaki İncelemeler” (s. 13-197) bölümünde Enginün Tanpınar'ın eserleri hakkında detaylı bilgiler verir. Eserlerinden hareketle onun sosyal, edebi

\footnotetext{
* Yüksek Lisans Öğrencisi, Kırşehir Ahi Evran Üniversitesi, Sosyal Bilimler Enstitüsü, Türk Dili ve Edebiyatı Ana Bilim Dalı, wefa-usta@hotmail.com, ORCID: 0000-0001-5361-4039
} 
ve ailevi hayatını da geniş bir çerçevede ele alır. Enginün; "Zaman Kırıntıları", "Huzur", "Beş Şehir", "Aydaki Kadın" eserleri üzerinden Tanpınar'ın ve çevresinin eserlerde nasıl konumlandığını gözler önüne serer. Onun mükemmeliyete ulaşma çabasını ele alır. İç dünyasının eserlerine yansımalarını, etrafında gördüğü şeyleri eserlerinde nasıl resmetmeye çalıştığını bu bölümde anlatır. Bu sonuçlara da Tanpınar'ın günlükleri vasıtasıyla ulaştığını izah eder.

“Son Durak: Zaman Kırıntıları" (s. 13-25) başlığı altında Enginün, Tanpınar'ın estetik zevklerine değinir. Şiirlerinden ve nesirlerinden örnekler vererek aslında onun estetiğinin bir bütünlük içinde olduğuna hükmeder. 1933 yılında yayımlanan "Ne Iç̧indeyim Zamanın" şiiriyle Tanpınar'ın şiir estetiğini bulduğunu buna bağlı kalarak da buradaki estetik ve sembolleri hayatı boyunca kullandığını söyler.

"Hangi Huzur?" (s. 25-27) başlığında "Huzur" romanının tahlili ve "Aydaki Kadın" (yarım kalan) romanıyla benzerliklerini anlatır. Enginün burada özellikle Suat karakteri ve romanın adının neden huzur olduğunun üzerinde durur.

"Sahnenin Dışındakiler" (s. 32-38) başlığında Enginün romanın içeriğine değinir. Enginün'e göre "Bir medeniyet krizi içinde yaşanan bir aşkın romanı olan "Huzur"un öncesi "Sahnenin Dışındakiler" ve onun da öncesi "Mahur Beste" yazarın öteki iki romanı "Huzur" ve Türk edebiyatının bir mizah şaheseri olan "Saatleri Ayarlama Enstitüsü" kadar dikkati çekmemiş ve üzerinde durulmamıştır." (s. 32) "Sahnenin Dışındakiler"de zaman 1920 yılıdır ve mekân İstanbul'dur. Enginün'e göre İstanbul hem sahnedir hem de sahnenin dışı. Ona göre asıl sahne Anadolu'dur. (s. 32) Romanın ihtivasından ve işlediği konulardan bahseden Enginün dağınık bir anlatım ile romanın diğer romanlarla birkaç benzer yanını ortaya koyarak bölüme son verir.

“Aydaki Kadın'ın Kaynakları Üzerine” (s. 38-60) başlığında bu romanın Tanpınar'ın mükemmeliyetçilik özelliği yüzünden yarım kalmasına değinir. Tanpınar'ın mükemmeliyetçi yapısı, romana devamlı bir şeyler ilave edip çıkarması sebebiyle roman nihayete erdirilemez. Enigünün'e göre Tanpınar, romanının bir türlü tamamen hazır olduğunu düşünmez ve yazıp bitirilemez. $\mathrm{Bu}$ sebeple de roman yarım kalır. Enginün, Güler Güven'in zor şartlar altında bu romanın kalan parçalarını bularak üzerinde yaptığı yoğun çalışmalar sonucunda tamamladığını belirtir. Tanpınar'ın son eseri olma mahiyetini taşıyan bu eserde, Tanpınar'ın Avrupa seyahatinin, resim sanatının ve V. Woolf'un yansımalarını görmek mümkündür. 19601 yıllarda bu eser ortaya çıkarken Tanpınar'ın fakirlikten, haklı şöhretinin bir türlü parlamamasından, çok okunmamasından yakınır. Enginün burada onun ikilem halindeki ruh ve düşünce dünyasını yansıtır.

Enginün, "Beş Şehir" (s. 60-66) başlığında roman ve deneme türlerinin arasındaki benzerlikler ve farklılıkları ortaya koyarak giriş yapar. Tanpınar'ın neden bu beş şehri seçtiğini, bu şehirlerin tarihi geçmişlerini ve mimarilerinin neler ifade ettiğini, beş şehrin ortak yönlerini, genel olarak romanların ana mekânının neden İstanbul olduğunu örneklerle detaylı bir şekilde anlatır. Bu eseri okuduktan sonra bu şehirleri görme arzusunun uyandığını da ilave eder. "Bursa, İstanbul Osmanlı 
Devleti'nin, Konya ve Erzurum Selçukluların önemli merkezlerinden, Ankara ise Osmanlının iki yıkılışının şahidi ve Türkiye Cumhuriyeti'nin başkenti." diyerek Tanpınar'ın bu şehirler ile arasındaki bağını ortaya koyar. Enginün, Tanpınar'ın bu şehirlerde bulunmasına rağmen onun romanlarındaki asıl mekânın daima İstanbul olmasını İstanbul'a olan tutkusuna bağlar. "Ankara ve dolayları "Teslim", "Eski Zaman Elbiseleri" adlı hikâyelerinde, Erzurum "Erzurumlu Tahsin"de, Bursa ise "Eski Zaman Elbiseleri"nde geçer. Konya ise hiçbir romanında yoktur." (s. 61) diyerek de diğer dört şehrin hikâye ve romanlarındaki yerinin azlığını belirtir.

İstanbul'u asıl mekânı seçen Tanpınar için Enginün: “Tanpınar çok sevdiği, kültürümüzün sembolü gibi gördüğü bu şehri her an yeniden keşfeder. İstanbul, sadece İstanbul'da yaşayanların şehri değildir. O gerçekten her insanın hasret duyduğu bir sevgili gibi andığı bir dünya şehridir." (s. 61) şeklinde düşünür. Enginün, Tanpınar'ın “Beş Şehir"deki İstanbul'a yaklaşımını, İstanbul'un yaşamının kendi efsanesini oluşturması sebebiyle şehirdeki masalsı havaya bağlar. Şehrin her yerindeki tarihi mimarî de bu havayı destekler niteliktedir. Tanpınar'ın çocukluğunun bu şehirde geçmesinin de ayrıca etkisi vardır. Enginün'e göre başka bir sebep ise Tanpınar'ın sanat mürşidi olarak gördüğü Yahya Kemal ile birlikte İstanbul'u dolaşma zevkidir. (s. 62) Enginün, bu sebeplerden ötürü Tanpınar'ın ana mekânının İstanbul olduğunu ileri sürer.

“Teslim” (s. 66-76) başlığı altında Enginün, Tanpınar ve kader bağlantısı kurar. Tanpınar'ın hikâyelerindeki kahramanlar sıradan insanlardır tanımını yaptıktan sonra buna en uygun hikâyenin de Teslim hikâyesi olduğunu belirtir. Bu hikâyeyi diğer hikâyelerle mukayese ederek Tanpınar'ın hikâyelerinin aslında biyografik okuma olduğunu belirtir. Buna Zeynep Kerman karşı çıksa da Enginün bu görüşü savunur. Bu hikâyedeki Emin Bey'in aslında bizzat Tanpınar olduğunu ifade eder. Hikâye genelinden Tanpınar özeline iner ve Tanpınar analizine devam eder. Enginün'ün bu yargıları, -herkesin fikir dünyası farklı olduğundan- kişiden kişiye farklılık gösterebileceği için bir kesinlik ifade etmez.

Enginün, “Tanpınar'ın Şiir Çalışması” (s. 85-93) başlığında Tanpınar'ın ilk şiiri olan "Musul Akşamları"ndan vefatına kadar olan dönemi kısa ama etkileyici örneklerle ele alır. Aslında onun nasir değil de şair olduğunu Tanpınar'ın sözleriyle ortaya koyar. Başta velud bir sanatçı olduğunu ancak Ahmet Haşim ve üstadı Yahya Kemal'den sonra şiir zevkinin oluştuğunu söyler. Bu etkileşimden sonra da şiir estetiği mükemmeliyete ulaşır. Bu mükemmeliyetçilik sebebiyle de birçok eseri yarım kalır.

Diğer bir önemli başlık ise "Tanpınar ve Semboller"dir (s. 139-147). Enginün bu bölüme Tanpınar'ın soyadını kendisinin tercih ettiğini söyleyerek başlar. Tan ve pınar sembollerine değindikten sonra eserlerindeki sembollere örnekler verir. Yılan, su, aydınlık, şehir, yüzmek, çember, zaman, örümcek ve eşik kavramları bunlara örnektir. Enginün, Tanpınar'ın bu sembolleri sürekli kullanması da onun eserleri arasındaki bağlarını güçlü kıldığını ifade eder. "Ruh ve sezginin sembolü güneş ve gün ışığıdır; bilinçaltının karanlık yanı ay ve gecedir.” (s. 139) Bu 
tahlilden sonra yılan, örümcek ve ă̆ sembollerinin üzerinde yoğunlaşarak Tanpınar'ın bolca kullandığı sembollere örnekler verir. Bu örneklerin başında da yılan sembolü gelir. Enginün, Tanpınar'ın eserinden bir alıntı yaparak “Onu her gördüğüm yerde tanıdım ve dünyamızda nasıl saltanat sürdüğünü gördüm. Balkan fecaatleri, Umumî Harbin sefaleti, yedi cephede girişilmiş savaş, hep onun, bu zalim ve kanlı meleğin üst üste takınmış olduğu çehrelerdi." (s. 141) Yılanın burada kader ve şeytan sembollerine dönüştügünü belirtir. Y1lan sembolüne Tanpınar'dan bir başka alıntıyla devam eder. "Ben gittikçe gençleşiyorum. Daima biraz daha gencim. Halklarım her gün biraz daha çevikleşiyor. Suda aydınlık gibi kayıyor, ormanda akşam gibi külçeleniyorum.” (s. 141) Burada da yılanın daima genç kaldığını ifade eder. Başka hikâyede ise Tanpınar'ın yılanı vicdan azabı yerine kullandığını da belirtir ama bunun analizine yönelmez. (s. 141)

“Tanpınar ve Çocuklar” (s. 158-172) başlığında Enginün, Tanpınar'ın sanatını çocuklar üzerine kurmadığını ancak çocuklara da sıkça yer verdiğini anlatır. "Huzur" romanı ile "Abdullah Efendi'nin Rüyalarl", "Teslim" ve "Yaz Gecesinde" hikâyelerinden örnekler vererek Tanpınar'ın hikâyelerindeki çocuk ile romanlarındaki çocuk kavramlarının farklı konumlandırıldığını belirtir. Enginün, Tanpınar'ın romanlarında çocukların daha önemli bir yer tuttuğunu söyler. "Mahur Beste"de çocuk ailenin mutluluğu değildir. İsmail Molla kendisine hiç benzemeyen c1lız oğlu Behçet'i sevmez, ama uzun yıllar sonra ona acır." (s. 162) burada Tanpınar'ın çocukları birer kahraman yerine arka plandan ibaret kullandığını belirtilir. Enginün'e göre bu romanda çocuk figürü 'hüzün' kaynağıdır. "Huzur" romanında ise "Çocukluğun mutlulukla birleştiği çocuk "Huzur"un Sabiha'sıdır. O masumiyetiyle çevresindekilerle oynayan zalim bir hükümdara benzer. Sevdiği ve sevmediklerini cezalandıran veya ödüllendiren küçük davranışlarıyla 'o evin masalı' anne ve babası içinse evliliği kurtaran, anneyi yeniden hayata bağlayan yaşama ve neşe kaynağıdır. Bu özelliğiyle Sabiha Tanpınar'ın çocuk kahramanları arasında yegânedir." (s. 163) diyerek Tanpınar'ın romanındaki diğer bir çocuk figürünü açıklar.

“Günümüze Yansımalarıyla Tanpınar” (s. 178-187) başlığında Enginün Tanpınar hakkında tanımlamalar yaparak bölüme giriş yapar. Tanpınar, Enginün'e göre yalnızlaştırılmış insandır. Onun görmezden gelinen adam olduğunu ifade eder. Tanpınar'ın yazdığı eserler üzerinden örnekler verirken Tanpınar'ın kendi yazdıklarına yaptığı tenkitler ile de onun aslında sükût suikastına uğradığını ortaya koyar. Günümüzde Tanpınar'a bu kadar rağbetin olmasını da sınıflandıran Enginün, bunların arasında en önemlisinin Mehmet Kaplan'ın onu derslerinde anlatması ve eserleri üzerinde çalışmalar yaptırmasına bağlar. Bunların dışında Tanpınar'ın hece ustası olduğunu ama serbest nazımı da denediği vurgular. Buradaki şu çarpıcı ifadesiyle de bölüm sona erer. Tanpınar Enginün'e göre nesilleri besleyen bereketli bir kaynaktır. (s. 182)

“Tanpınar ve Mehmet Kaplan” (s. 187-197) başlığında Tanpınar'ın mektup ve müsveddelerinden yola çıkarak Kaplan ve Tanpınar arasındaki anılara değinilip aralarındaki güçlü bağa ve hoca talebe ilişkilerini anlatılır. 
“Tanpınar'la İlgili Söyleşiler” (s. 200-239) bölümünde Enginün'ün Tanpınar ile ilgili yaptığı röportajlar, dergi röportajları ve Pertevniyal Lisesi öğrencileriyle yaptığı söyleşi yer alır. Enginün bu bölümde Tanpınar'ı (onu tanıyan tanımayan) herkesin sevdiğini belirtip ancak pek çoğunun onu okumadığından yakınır. Enginün ve Zeynep Kerman Tanpınar'ın günlüklerinden yola çıkarak onun karakterine, sanatçıllı̆ına ve özel hayatına dair kesitler sunar.

Enginün, Tanpınar'ın romanlarındaki kahramanları çevresinden seçtiğini düşünür. Buna da "Saatleri Ayarlama Enstitüsü"ndeki ispiritizmacı Taflan Deva'nın Peyami Safa olduğunu söyleyerek örnek verir. Yine "Mahur Beste"deki Ata Molla'nın Nurullah Ataç olduğunu ileri sürer. (s. 221)

Tanpınar hakkında özel hayatına da değinen Enginün onun 27 Mayıs günlerine de atıfta bulunur. Tanpınar'ın pek bilinmeyen bir yanını 'Günlüklerde beni dehşete düşüren, askerî müdahaleyi büyük bir sevinçle karşılaması, alkışlaması ve Demokrat Partilileri yöneltilen suçlamaların idam edilmesine yetmeyeceğini düşünerek üzülmesi oldu. Bu tuhaf bir ruh hâli?” (s. 222) diye düşünerek ortaya çıkarır.

“Günlükler Işı̆ğında Tanpınar'la Baş Başa” adlı bölümde Zeynep Kerman'ın Tanpınar hakkındaki günlüklerinde yer alan "Kendisine hayatı boyunca tesir eden, Harbiye'deki mevkufiyet günleri hakkındaki ifadelerin 'üstü örtülü'. Bu belki de kendi kendine bile itiraftan çekindiği, baskısını ömür boyu hissettiği bir korkunun neticesi. Bunun duyulması ihtimali bile onu paniğe sevk ediyor." (s. 231) sözleri de Tanpınar hakkında bilinmeyen tutukluluk sürecini ortaya çıkarır.

Enginün, Tanpınar'ın kitaplarına düşkünlüğünü yine onun günlüğünden yaptığı alıntı ile nakleder: "Irak fikri beni gittikçe sarıyor! Birkaç bin lira para. Fakat kitaplarımdan nasıl ayrılacağım!"” (s. 234)

“Tanpınar'ın Kitaplarına Önsözler ve Bazı Değerlendirmeler” (s. 239-279) bölümünde Enginün'ün Tanpınar'ın bazı eserlerine yazdığı önsözler ve Tanpınar hakkındaki birkaç değerlendirmesi yer alır.

Kitabın diğer bölümleri ilk bölümü tekrarlar ve özetler mahiyettedir. Kitap başlı başına Tanpınar hakkında eşsiz bir eser niteliği taşır. Yapılan araştırmalar, başvurulan kaynak kişiler ve elde edilen evraklar sayesinde Tanpınar bu kitaba sığdırılmıştır.

Kitapta bazı bölümlerde aynı konularda tekrara düşülmesine, kitabın sonlarına doğru artan imla hatalarına rağmen bu eser Tanpınar'ı tanımak için başucu eseri niteliğindedir. Yalnız Enginün'ün de dediği gibi Tanpınar'ı anlamak isteyen onun hakkında yazılanları değil bizzat onu okumalıdır. Eserlerindeki mükemmeliyeti musikiyle, resimle ve diğer sanat dallarıyla nasıl harmanladığını anlamak ancak onu okumaktan geçer. Onun şiir ve nesirleri bir arada düşünüldügünde özgün bir bütünlük inşa ettiği onu tanıyan ve eserlerini okuyan herkesçe malumdur.

İnci Enginün, gerek sayısız konferans ve seminerleriyle gerekse (kendi tabiriyle) iyi bir araştırmacı olması hasebiyle Ahmet Hamdi Tanpınar hakkında detaylı 
bilgilere sahiptir. Bu eser Tanpınar'a, Enginün'ün ufuk ve penceresinden bakma firsatı da sunar. Samimiyete dayalı bir üslupla ele alınan bu eser, içerdiği zengin bilgi hazinesi, harcanan emek ve yapılan mesailerle; Tanpınar'ın eserleri, hayatı ve sanatı hakkında özgün bir konuma sahiptir. Kendi alanına sağladığı katkıyla beraber tespitleri, kendine has değerlendirmeleriyle yapılacak yeni çalışmalara kaynaklık etmesi bakımından eser ciddi manada önem taşır. 